\title{
LAS ENCRUCIJADAS DEL PERIODISTA SOBRE ASUNTOS COMUNITARIOS: PERIODISMO, NACIONALISMO Y EUROPEÍSMO
}

\section{Resumen:}

El periodismo realizado por los corresponsales de prensa en Bruselas tiene por objeto un proceso político supranacional y transnacional, el propio de la unificación europea, pero, al mismo tiempo, es un periodismo hecho también en clave nacional. Esta interacción simultánea de lo supranacional, lo transnacional y lo nacional convierte al periodismo que practican los corresponsales de prensa en Bruselas en un tipo muy particular de periodismo. En este sentido, resulta plenamente justificado el estudio de los condicionamientos ideológico-culturales de estos corresponsales en relación con su labor profesional.

Palabras clave: Periodismo, europeísmo, europeidad, nacionalidad, Unión Europea.

\author{
Joaquín Sotelo González \\ (Universidad Complutense de Madrid) \\ joaquin.sotelo@gmail.com
}

\begin{abstract}
:
Journalism in Brussels is both addressed to by, and is addressing, a supra-national, and trans-national political process, that of the European unification, while at the same time, it is further positioned within national discourses, in that it is addressing a national public. This simultaneous interaction of the supra-national, in terms of the European institutions which are predominantly covered by the EU correspondents, the trans-national, in terms of the various inter-governmental meetings and summits, and the national, in terms both of national politics as well as of national publics, renders Brussels journalism a very particular one. It is in this sense that a study of its articulation with constructions of nationality and Europeanness is further warranted.
\end{abstract}

Keywords: Journalism, Europeism, Europeanness, nationhood, European Union.

\section{INTRODUCCIÓN}

C Cuál es la actitud -o las actitudes- del periodista respecto al objeto/sujeto de su información? ¿Existen prejuicios o preconcepciones respecto al hecho noticioso que, de alguna manera, condicionan el comportamiento profesional y, por tanto, los resultados del trabajo del periodista? A través de una serie de investigaciones llevadas a cabo durante los últimos años, hemos tratado de encontrar res- 
Las encrucijadas del periodista sobre asuntos comunitarios...

puestas a estas preguntas de boca de los propios profesionales de la información. Para ello, hemos tomado como referencia el trabajo de los corresponsales de prensa europeos destacados en Bruselas y su objeto informativo de principal interés: los asuntos relacionados con la Unión Europea. A través de la recopilación de una serie de testimonios profesionales, hemos tratado de establecer un mapa de coordenadas para un eventual espacio periodístico europeo concreto en función de cuatro variables: el periodista-corresponsal de prensa, el proceso político objeto de su información, la noticia impresa y la audiencia.

Es nuestra intención ahora retomar algunas de las apreciaciones por nosotros recogidas, tanto en tiempo de ejercicio profesional, como en tiempo de investigación propiamente dicha, y complementarlas con las de otros investigadores con objetos de interés afines a los nuestros, para tratar de dar respuesta a los interrogantes con los que abríamos este artículo. En definitiva, nos proponemos indagar en los sentidos periodísticos que los conceptos de nación y Europa cobran en el imaginario de esos corresponsales y cómo tales conceptos condicionan, si es que lo hacen, su labor profesional.

Puede decirse que el periodismo sobre asuntos comunitarios tiene un carácter tridimensional, porque se dirige a un proceso político tanto supranacional como transnacional, pero, al mismo tiempo, se sitúa dentro de los discursos políticos nacionales. Es supranacional desde el momento en que existen instituciones europeas en las que los gobiernos nacionales han delegado parcelas de soberanía y que son cubiertas, informativamente hablando, por determinados corresponsales. Es transnacional en cuanto al gran número de reuniones intergubernamentales. Y es nacional, tanto en términos de política nacional implicada en el proceso, como en términos de público.

Nación y Europa -nacionalidad y europeidad-son concebidas aquí como las dos caras de una misma moneda. La cuestión que guía el análisis es la pregunta sobre la condición creada para un periodismo europeo dados los diferentes significados/definiciones de nación, de Europa y de periodismo. En definitiva, hemos buscado una articulación de ideas y conceptos en el sentido en que Laclau y Mouffe (1985; 1986) utilizan este término -articulación- para referirse a la fusión o sutura de diferentes discursos en puntos nodales, en el caso que nos ocupa, los discursos en torno a las nacionalidades, la europeidad y el periodismo. A través de tal articulación, pretendemos indagar en el espectro de posturas profesionales en relación con el tratamiento periodístico dado por los corresponsales de prensa en Bruselas a los asuntos relacionados con la Unión Europea.

Con nuestra labor de investigación hemos tratado de colmar cierto vacío en la literatura científica existente al respecto del tratamiento periodístico que se le brinda a los asuntos comunitarios. La mayor parte de trabajos previos en esta materia se han elaborado a partir de técnicas de análisis de contenidos, tanto de carácter cuantitativo como cualitativo, y tomando como referente acontecimientos concretos y periodos de tiempo limitados.

Durante los años noventa del pasado siglo XX, la Fundación para el Desarrollo de la Función Social de las Comunicaciones (Fundesco) y la Asociación de Periodistas Europeos (APE) publicaron una serie de cinco informes que, bajo el genérico título 
de Infoeuropa y dirigidos por el profesor Bernardo Díaz Nosty, ofrecían estudios sobre el tratamiento periodístico dado por algunos medios españoles a los asuntos de la Unión Europea. El primero de aquellos informes se publicó en 1991 con el título Los medios en la construcción de la unidad europea (Análisis de la información sobre la CE en la prensa y la televisión españolas). Los siguientes informes, publicados sucesivamente en los años 1993, 1994, 1995 y 1996, lo hicieron bajo el título La Unión Europea en los medios de comunicación. La reestructuración de Fundesco en torno al año de la publicación del último informe de Infoeuropa (1996) truncó definitivamente aquella serie iniciada en 1991. Ya en 2002 y de nuevo bajo la dirección del profesor Díaz Nosty, la Asociación de Periodistas Europeos publicó Infoeuropa 2002: La prensa diaria en la UE. Estructura y proyección digital, obra que encontró continuidad al año siguiente (2003) en La prensa diaria en la UE. No obstante, ambas publicaciones, más que dar continuidad a la serie de Infoeuropa de los años anteriormente citados, se limitaban a describir la situación de la prensa escrita y digital en los distintos países de la Unión Europea.

Los Infoeuropa publicados en los años noventa se construyeron básicamente sobre exhaustivos y minuciosos análisis cuantitativos de contenido. Y esta técnica ha sido la más socorrida también por investigadores posteriores interesados igualmente en este objeto de estudio.

Gran parte de los trabajos académicos de análisis e investigación realizados durante los últimos años al respecto de medios de comunicación y construcción europea han tomado como referente acontecimientos comunitarios de relevancia, tales como la implantación de la moneda única europea, la incorporación de nuevos Estados miembro (especialmente, la gran ampliación comunitaria de mayo de 2004) o los referenda nacionales sobre el proyecto de Tratado Constitucional para Europa. Así, por ejemplo, los trabajos de Vicente Pérez Plaza (1999); Roland Pepermans y Anke Müller-Peters (1999); Holli A. Semetko y Patti M. Valkenburg (2000); Claes H. de Vreese (2001); Jochen Peter, Holly A. Semetko y Claes H. de Vreese (2001, 2003); Olaf Werder (2002); Anna Triandafyllidou (2003); Stephan Russ-Mohl (2003) y otros. Casi todos estos trabajos se han centrado en el estudio de la visibilidad en la prensa diaria y en los informativos de televisión de las noticias sobre la Unión Europea, pero su foco se ha mantenido al margen del estudio del periodista-corresponsal como factor crítico de la elaboración de este tipo de información. Y es aquí donde precisamente resulta relativamente novedosa nuestra aportación, con la que tratamos de profundizar en las motivaciones del profesional y en los contextos socioculturales que de una manera u otra condicionan el resultado del trabajo periodístico de los corresponsales en Bruselas.

\section{METODOLOGÍA, HIPÓTESIS, FUENTES Y OBJETIVOS}

Para llevar a cabo nuestro estudio, hemos entrevistado a más de veinte corresponsales de prensa de trece nacionalidades distintas -doce de ellas correspondientes a países comunitarios- que desarrollan o han desarrollado parte de su labor profesional en Bruselas. Siempre que ha sido posible, la entrevista ha sido temáticamente concebida siguiendo tres pautas que Blumler y Gurevitch (Blumler; Gurevitch, 1995) identifican como básicas en un sistema de comunicación política: la dimensión comunicativa de las instituciones políticas; la dimensión política de los medios de comunicación y las audiencias. 
Las encrucijadas del periodista sobre asuntos comunitarios...

La metodología que hemos empleado para la realización del presente estudio es una variante del método analítico-discursivo, muy en la línea de los trabajos de Jonathan Potter y Margaret Wetherell (Potter, 1996; Potter y Wetherell, 1987; Wetherell, 1998). Este tipo de análisis discursivo incorpora elementos de constructivismo y de teoría post-estructuralista. A diferencia del más marcado carácter historicista del marco analítico-discursivo empleado por Michel Foucault, el de Potter y Wetherell atiende a parámetros más localistas, pero sin descuidar tampoco cierta sensibilidad historicista, lo que dota a este método de análisis de una versatilidad muy apropiada a la hora de construir los diversos significados asociados al periodismo europeo en relación con los testimonios de los corresponsales entrevistados. En particular, resulta especialmente útil la metáfora del repertorio interpretativo utilizada por estos autores:

Los términos, descripciones y figuras del discurso se ensamblan y cobran sentido a menudo en torno a vívidas imágenes. En lenguaje estructuralista podríamos hablar de sistemas de significados y de piedras miliares sobre las que construir versiones de acciones, propias y sociales, que se constituyen como fuentes para hacer evaluaciones [...] (Potter; Wetherell, 1992: 90).

La construcción de repertorios interpretativos se basa en lo que dice la gente y en cómo dota esa gente que habla de sentido a su mundo, y al mismo tiempo, orienta sobre el discurso en el sentido de las representaciones que, en nuestro caso, los entrevistados, ofrecen de los objetos y sujetos sobre los que se expresan. Si el objetivo del análisis es descifrar los tipos de objetos y de sujetos que se construyen a través de textos (periodísticos), entonces, la noción de repertorio interpretativo aportada por Potter y Wetherell se muestra como muy apropiada y especialmente indicada cuando se trata del asunto de arrojar luz sobre en qué consiste el periodismo europeo y cuáles son sus variantes y los usos que de él hacen los corresponsales de prensa. Teniendo en cuenta que el periodismo es un espacio de significados abierto, la noción de repertorio interpretativo puede servirnos muy eficazmente como herramienta analítica con la que organizar el material que nos encontramos dentro de ese espacio.

Una vez apuntada la principal herramienta analítica utilizada para la realización del presente trabajo, nos detenemos ahora en los pasos que hemos seguido para realizar este estudio empírico. El material objeto de nuestro análisis ha consistido en una serie de entrevistas realizadas a corresponsales de prensa especializados en asuntos relativos a la Unión Europea. Se trata de veintidós entrevistas en profundidad, veinte de las cuales fueron íntegramente transcritas, de desigual duración, desde cuarenta y cinco minutos a dos horas. La mayor parte de los entrevistados resultaron ser hombres (únicamente seis mujeres). La elección de los entrevistados, más que a criterios deliberados o aleatorios, respondió a la ambición de cubrir el más amplio rango posible de discursos periodísticos en relación con los asuntos comunitarios europeos $y$, efectivamente, consideramos que las entrevistas realizadas cubrieron tal pretendida amplitud de rango. La unidad de análisis fue, por lo tanto, el discurso de los entrevistados y no cualquier otra consideración.

Una vez obtenidos los testimonios pertinentes, nuestro esfuerzo se ha centrado en procesar toda la información conseguida en busca de una eventual construcción teórica de carácter explicativo y, en su caso, también clasificador, de los registros 
periodísticos relativos a asuntos de la Unión Europea. Las respuestas obtenidas mediante las entrevistas realizadas han sido analizadas básicamente sobre la base de dos cuestiones: qué es la nación y qué es Europa. Y esas preguntas y sus correspondientes respuestas nos han conducido a las diferentes ideas construidas en torno a los conceptos de nación y Europa. Tales versiones derivan finalmente en una perspectiva desde la que la nacionalidad es vista en términos similares al propio periodismo, es decir, como un espacio de significados abierto, una arena de diversidad e, incluso, de contradicciones.

El principal objetivo de nuestra labor ha sido tratar de identificar o reconstruir las variantes periodísticas encontradas en los discursos de los corresponsales entrevistados y profundizar así, a la postre, en el estudio de los condicionamientos culturales y nacionales de los periodistas que informan, opinan y/o interpretan sobre asuntos de la Unión Europea. Las hipótesis de partida que pretendemos verificar son, primero, la de la existencia de determinados condicionamientos ideológico-culturales del corresponsal de prensa que desarrolla su labor en Bruselas y, segundo, la influencia de tales condicionamientos sobre los resultados periodísticos del trabajo de esos corresponsales. Y bajo estas premisas, presentamos a continuación los resultados de nuestras indagaciones.

\section{LO EUROPEO Y LO NACIONAL: SIMBIOSIS IMPOSIBLE}

Las naciones existen en virtud de particularidades por las que se diferencian unas de otras. Lo diferente, lo particular, constituye la esencia de la nación, el elemento sustantivo que permite hablar de una entidad genuina, única, exclusiva, distinta a las demás. Se trata de algo inherente o congénito a la propia entidad nacional que le da sentido.

Una Unión Europea con naciones gobernadas por políticos de ideologías afines no tiene garantizada una mayor unidad:

[...] Creo que la división creada por los intereses nacionales -le dice un corresponsal a nuestra colega Eugenia Siapera- es más fuerte, también lo cultural, los británicos son mucho más euroescépticos, yo diría genéticamente [...]. En Grecia, por ejemplo, los periodistas están más marcados por la solidaridad ortodoxa que por la atlantista [en referencia a la OTAN] y por la comunitaria (Siapera, 2002: 148).

Las tradiciones político-culturales de cada nación tamizan las percepciones, primero, y consecuentemente, las conductas, después, de sus ciudadanos. La cultura parlamentaria alemana, inexistente, por ejemplo, en Francia, indudablemente se traduce en un mayor respeto de los alemanes hacia la institución del Parlamento que el profesado por los franceses a esta institución.

Que el hecho diferencial nacional también tiene evidentes efectos sobre los resultados de la labor de los corresponsales de prensa en Bruselas se hace explícito en estas palabras de un periodista finés:

El periodismo finlandés presta mucha atención al proceso de toma de decisiones, como en todas partes, por supuesto, pero nosotros no tenemos esta magnitud de sentimiento hacia Europa, no sé [...]. Algunas veces, nos reímos entre colegas de 
Las encrucijadas del periodista sobre asuntos comunitarios...

las diferencias entre sus enfoques y los nuestros, entre lo que ellos escriben y lo que escribimos nosotros (Siapera, 2002: 148).

A veces, la exclusividad nacional sentida deriva en patriotismos incondicionales, como el detectado por Cristina Pérez-Cantó, en su función de jefa del Gabinete de Prensa de la Secretaría de Estado para las Comunidades Europeas, dependiente del Ministerio de Asuntos Exteriores español:

Los ingleses son aficionados a intoxicar en los Consejos [Europeos]; y te puedes encontrar a un miembro de su delegación por los pasillos haciendo declaraciones falsas para poner a la opinión pública de algún otro país a favor de los intereses ingleses (Sánchez Martínez, 1994: 47).

También Cristina Buhigas Arizcún, en calidad de jefa de la Sección de Europa del diario La Gaceta de los Negocios, advertía en el mismo foro:

También hay que tener cuidado con [la agencia de noticias] France Press porque suele hacer patria, es decir, por defender la postura francesa llega incluso a mentir en determinadas informaciones, aunque lo ofrece como verdad universal (Sánchez Martínez, 1994: 51).

Evidentemente, puede decirse tanto que el hecho diferencial de cada nación lo impregna todo, como que es todo lo que conforma precisamente ese hecho diferencial, de manera que puede ser éste el que explique los condicionamientos de las relaciones internacionales y de los resultados periodísticos nacionales o pueden ser precisamente esas formas de relaciones y esos resultados periodísticos lo que constituya el hecho diferencial. En cualquier caso, es evidente la existencia de elementos distintivos entre las naciones. Y este hecho puede ser entendido a primera vista como claramente incompatible con un proyecto de unificación e integración como el europeo. Aún más, puede decirse que tal proyecto sería una amenaza para la supervivencia de las nacionalidades, planteadas precisamente a partir de sus hechos diferenciales. El proyecto europeo se presenta entonces como algo no sólo imposible, sino indeseable:

Los alemanes [...] están obsesionados con el Parlamento y la democracia, como los noreuropeos lo están con la transparencia y la claridad, y los españoles con los tomates y la pesca, y los griegos con las subvenciones al tabaco [...], cada país tiene sus propias prioridades, sus propias agendas [...] (Siapera, 2002: 149).

Y es cierto que tras cada reunión del Consejo de Ministros de la Unión Europea, los representantes de cada uno de los Estados miembros de la Unión comparecen simultáneamente en sendas ruedas de prensa para informar a los periodistas de sus respectivos países sobre los logros obtenidos para su nación en las negociaciones. Y siempre son presentados como un éxito político doméstico:

Puede suceder y sucede todas las semanas [...] que de un mismo hecho se presenten diversas versiones enfrentadas entre sí, bien sea en cuestiones esenciales o de matiz, y es bastante fácil que la versión que da la Comisión pueda estar enfrentada por cuestión de intereses políticos o por intereses electorales, con la que le interesa dar al gobierno de turno. Esto se produce en los doce Estados miembros 
[la cita es de 1993], gobierne quien gobierne; es algo inherente a la propia dinámica de la construcción europea (Sánchez Martínez, 1994: 18).

Tampoco faltan ocasiones en las que se ha detectado favoritismo comunitario hacia ciertos países en detrimento de otros. Ya la propia inacabable y socorrida repetición del número de Estados miembros de la Unión Europea para referirse a la Unión en su conjunto -los Doce, los Quince, los Veinticinco...- entraña énfasis en la división, en la fragmentación, en la irreductibilidad de varios a uno sólo.

Un análisis somero del entramado institucional comunitario también da idea de la dispersión de intereses y del confusionismo reinante en la Unión:

Son quince países trabajando juntos -decía un corresponsal en Bruselas en 2003cada uno con sus intereses, con su punto de vista y esto durará años, si llega a cambiar, que lo dudo (Siapera, 2002: 151).

El dilema de la existencia simultánea del proyecto comunitario y de la nación coloca a ambos en posición antagónica, hasta el punto de tener que elegir entre uno y otro:

La Unión Europea [...] es un institución que de hecho e inevitablemente toma poder de los gobiernos nacionales, toma soberanía de los gobiernos nacionales, algo sobre lo que no estoy ahora emitiendo un juicio de valor, no digo si pienso que esto es bueno, para mi periódico es muy malo (Siapera, 2002: 151).

O como decía Félix Monteira en 1993:

La Comisión Europea aún no dispone de suficiente presupuesto como para compararse con el de un Estado, y por tanto depende de los Estados miembros, que en tiempo de crisis jamás han tenido suficiente dinero para invertir en unión europea; así que, cuando llegan las crisis, es el momento en que cada país se vuelve egoísta para intentar salir de la coyuntura desfavorable solucionando su situación interna (Sánchez Martínez, 1994: 34).

\subsection{El periodismo euroescéptico}

El espacio periodístico que surge del posicionamiento ideológico anteriormente descrito es el del denominado eufemísticamente periodismo euroescéptico o, si se prefiere, antieuropeísta, caracterizado por un particular tratamiento de los asuntos comunitarios, muy bien ejemplarizado en parte de la prensa británica, interesada sólo en la vertiente nacional de los asuntos europeos. De hecho, para muchos, las divisiones entre eurófilos y euroescépticos en el Reino Unido se fundan en las distintas maneras de afrontar el hecho identitario británico. Dada la relevancia del registro del periodismo euroescéptico en las páginas de gran parte de los diarios británicos y, consecuentemente, la especial pertinencia a nuestros fines, consideramos atingente detener nuestra atención preferentemente en este caso.

Para Thomas Risse, la política comunitaria británica es fiel reflejo de la percepción identitaria del colectivo: 
Las encrucijadas del periodista sobre asuntos comunitarios...

Más de veinte años después de la entrada en la Comunidad Europea, la mayor parte de la elite política británica todavía considera Gran Bretaña como de más que en Europa [...]. Hay aún un sentimiento de ellos frente a nosotros entre Gran Bretaña y el continente (Risse, 1998: [en línea]).

Basta recordar aquellas palabras de Robin Cook en su discurso del 9 de junio de 1997 a la Cámara de los Comunes en las que, el a la sazón secretario de Exteriores británico, situaba a Gran Bretaña fuera de Europa:

Una de las cosas que hemos aprendido los que hemos ido a Europa es que también allí hay un cambio de opinión. [...] Cuando yo fui por primera vez a Europa, al primer político europeo que conocí fue a Lionel Jospin (Risse, 1998: [en línea]).

A propósito de hechos identitarios, Anna Triandafyllidou observa lo siguiente:

[...] el uso del término identidad nacional en el caso británico puede ser juzgado impropio desde el momento en que el Reino Unido comprende cuatro naciones distintas, los ingleses, los irlandeses, los escoceses y los galeses (Triandafyllidou, 2002: 121-122).

La autora recuerda la propuesta de Hugh Kearney de hablar mejor de comunidad nacional británica como una más acertada conceptualización de cuatro naciones en una. Es cierto que, si aceptamos la existencia de varios niveles de identidad, la distinción entre englishness y britishness a menudo se desdibuja. El juego terminológico llega hasta la propia prensa. The Times utiliza los términos Britain, United Kingdom y British de forma intercambiable para referirse a la sociedad británica y/o a United Kingdom como Estado. Daily Mail, por el contrario, apenas usa el término United Kingdom y opta por Britain o the British people o the nation.

Pues bien, este es el caso en el que está envuelto el discurso político -y también, en gran medida, el mediático- británico, más tendente a la identificación colectiva con los símbolos, la historia y las instituciones nacionales que con los símbolos, la historia y las instituciones europeas. Y es difícil conciliar estos elementos con una visión política de orden europeo que vaya más allá de un mero intergubernamentalismo.

Así, mientras la Corona británica simboliza la soberanía externa frente a Roma, al Papa y, en general, frente al continente desde el año 1066; el Parlamento simboliza la soberanía interna en la que se basan unos principios constitucionales de más de setecientos años de antigüedad ganados en los campos de batalla. La soberanía británica está muy ligada a los mitos. Pero es probable que las objeciones a su transferencia tengan más que ver con el asunto de la identidad nacional que con el de la responsabilidad -0 , en su caso, irresponsabilidad- política de las autoridades comunitarias. Porque aunque a menudo se apele a la falta de democracia, de transparencia y de control de las instituciones europeas para justificar la no cesión de competencias, tiene que haber algo más. Si simplemente fuera una cuestión de más democracia, no se levantaría tanto la voz en Gran Bretaña ante las propuestas de robustecimiento de los poderes del Parlamento europeo.

También el pasado histórico desempeña una función en el imaginario colectivo británico. La Commonwealth y la especial relación con Estados Unidos, a menudo 
aludida como objeción a un mayor compromiso con la Unión Europea, son parte de una herencia post-imperial en la que también se inscribe cierta ilusión de grandeza, utilizando palabras de Stephen George, y la nostalgia de una posición de mayor peso relativo en el escenario internacional tras la segunda guerra mundial.

La libra esterlina es otro de los poderosos símbolos de las viejas glorias británicas y del excepcionalismo inglés. Cuando en 1993 el Sistema Monetario Europeo entró en crisis, el Gobierno británico trató de evitar por todos los medios la humillación de una devaluación que finalmente se produjo y que, para muchos, alimentó aún más al euroescepticismo. El euro es un gran paso hacia la integración política y hacia el supranacionalismo institucional europeo, precisamente todo aquello a lo que se opone una parte importante de los británicos, que ven en Bruselas y en Frankfurt una auténtica amenaza a su exc/usividad.

A grandes rasgos y teniendo en cuenta sólo diarios nacionales, el panorama periodístico británico se divide en dos grandes tipos de prensa: por un lado, los broadsheets y, por otro, los tabloids. Tanto en un grupo como en el otro existen periódicos de línea editorial euroescéptica y periódicos de línea editorial europeísta. Entre los broadsheets euroescépticos se encuadran The Times y The Daily Telegraph, y en el lado europeísta Independent, The Guardian y Financial Times. Por lo que a tabloids se refiere, The Sun, Daily Mail y Daily Express son los grandes abanderados del euroescepticismo, mientras que el Daily Mirror está más próximo a tesis europeístas. Traducido a cifras de circulación, esto significa más de ocho millones y medio de ejemplares diarios de corte euroescéptico y unos tres millones y medio de corte europeísta. Y a lo cuantitativo habría que sumarle lo cualitativo, es decir, el grado de compromiso que cada cabecera tiene con sus tesis ideológicas y que, por lo general, lleva a los euroescépticos a defender sus posturas con más vehemencia que la que emplean los europeístas en defender las suyas.

En definitiva, y retomando el hilo del registro periodístico alumbrado de la consideración de la simbiosis imposible de los conceptos de nación y Europa, el espacio profesional que surge es el de la transmisión de noticias comunitarias desde la perspectiva del interés nacional, lo que desemboca en un periodismo europeo orientado casi exclusivamente a la cobertura y transmisión de noticias con vertiente nacional:

Mi trabajo aquí -le comenta un corresponsal a Siapera- es estar políticamente muy alerta, relacionar el relato europeo con el británico [...], concienciar a la gente de que este proyecto es enorme, que tiene profundas implicaciones [...], que la Unión Europea no es sólo un cuerpo distante que toma aburridas decisiones que pueden o no afectar a sus vidas, es una institución que de hecho afecta en la que el poder miente [...], lo que sucede aquí [...] no es únicamente una historia importante por sí misma, es una historia muy importante en relación con la política británica, porque significa que Tony Blair está apoyando [...] la transferencia de poder (Siapera, 2002: 155).

No resulta extraño encontrar en las páginas periodísticas británicas muestras de periodismo euroescéptico obstinado en explicar, a propósito de los análisis del proceso político comunitario, por qué no interesa el proyecto europeo. Y tampoco sorprende que los corresponsales consideren que el periodismo europeo más vendible 
Las encrucijadas del periodista sobre asuntos comunitarios...

sea el más estrechamente conectado por su contenido con las personas y los asuntos domésticos, es decir, el más angulado hacia lo nacional.

\section{CUANDO LA NACIÓN ES SECUNDARIA Y LO IMPORTANTE ES EUROPA}

Si antes hablábamos de lo problemático que resulta el proyecto de integración europea para la nación, ahora lo haremos desde el punto de vista contrario, es decir, cuando el problema es la nacionalidad, que pasa a ser vista como un obstáculo para el proyecto de integración continental que debe ser superado, que debe ser dejado atrás, porque forma parte de un pasado asociado a viejas maneras de actuar incompatibles con el futuro abierto, como le apuntaba este corresponsal a Eugenia Siapera:

Pensamos como si todavía estuviéramos en los tiempos del viejo Estado-nación, que ha sido superado por las circunstancias en muchos aspectos, en muchas funciones, así que los medios deberían intentar, no a corto plazo, pero sí a medio, establecer verdaderas delegaciones, [...] delegaciones significativas, incluso numéricamente, aquí en Bruselas (Siapera, 2002: 159).

Ahora, la multiplicidad y el pluralismo se convierten en un auténtico contratiempo:

Lo negativo es que nosotros [los corresponsales en Bruselas] debemos hacer frente a las muy diferentes prioridades de los lectores de quince países. Esto se hace muy manifiesto si ves una sesión informativa, porque la prensa concernida no es la misma, dado que buscamos historias con perspectiva nacional, o historias europeas desde un punto de vista doméstico, [...] pero tengo la impresión de que algo se mueve, es realmente el principio del principio (Siapera, 2002: 160).

Repárese en el hecho de que lo que ahora se critica no es la existencia de naciones, sino determinada concepción del hecho diferencial nacional que, a veces y para según quién, da forma y sentido a las naciones. La solución pasa por una homogeneización, por una neutralización de las diferencias, una superación de cierto concepto de nacionalidad a través de la creación de una Europa auténticamente comunitaria basada en el consenso; es decir, una Europa con una sola voz y con una opinión pública común de la que hoy carece:

Europa tiene tantas opiniones públicas como países, puede que más, mira las diferencias a la hora de afrontar la guerra, los británicos, los alemanes, los italianos, los griegos, los franceses, son casi incomprensibles, ¿te imaginas a Europa en la guerra con diez opiniones públicas detrás? (Siapera, 2002: 161).

La cita anterior se refería a la guerra de Kosovo de finales del siglo XX, pero también es plenamente válida -y más aún incluyendo a los españoles- para la de Irak del año 2003. Sobran las evidencias de la carencia de una opinión pública europea y de los problemas a ello asociados, como que tras cada Consejo Europeo y el consiguiente repaso de las prensas nacionales, más que parecer que se haya celebrado un Consejo, parezca que se hayan celebrado tantos como países integran la Unión Europea:

Esta representación de corresponsalías [la de Bruselas] es la mayor del mundo, uno de los más grandes proyectos colectivos internacionales jamás emprendidos y 
Joaquín Sotelo González

[conseguir] un servicio de prensa efectivo creo que va a llevar tanto como lleve la propia evolución de todo el sistema, [...] y probablemente será muy difícil hasta que [...] las formas de hacer las cosas nacionales sean reemplazadas por una forma europea de llevarlas a cabo comúnmente aceptada, y hasta que no sea así, habrá problemas (Siapera, 2002: 162).

El sistema de portavocías de los comisarios europeos, más tendente siempre a representar al comisario (político) que a la institución supranacional (la Comisión Europea), tampoco es precisamente un buen ejemplo acorde con los objetivos teóricos perseguidos con la Unión. En definitiva, el hilo conductor ahora parece ser la necesidad de una opinión pública homogénea como condición sine qua non para una verdadera y efectiva Unión Europea.

Si en el anterior apartado, nación y Europa se presentaban como incompatibles y aun como contradictorias, ahora sucede lo mismo, sólo que ahora el problema es la nación, a la inversa que antes:

A pesar -dice Félix Monteira- de que los gobernantes crean hoy en día que la forma mejor de organización social es el Estado-nación, no se puede olvidar que éste fue un invento de no hace más de 500 años, cifra bastante ridícula comparada con la historia de la humanidad. El proceso hacia la unidad es lógico e irreversible (Sánchez Martínez, 1994: 34).

El dilema de esa incompatibilidad es en esta ocasión resuelto con la predominancia de Europa y su proyecto unificador. La estrategia para conseguir sacar adelante tal proyecto pasa, entre otras claves, por la existencia de una opinión pública europea, idea sobre la que también ha abundado con frecuencia Jürgen Habermas como condición de una Europa unida y democrática.

\subsection{El periodismo europeísta}

El espacio periodístico que surge del posicionamiento ideológico descrito bajo el último epígrafe es el del denominado periodismo europeísta, un registro basado en la difusión de información europea desde un punto de vista puramente europeo.

En los registros periodísticos europeístas encontramos realmente un compromiso que justifica la intervención periodística en el proceso político de europeización en aras a la conformación de una opinión pública europea:

Es algo que compete a la prensa que está en Bruselas, dice un corresponsal, porque depende muchísimo de nosotros la aparición de una sola opinión pública, que para mí es muchísimo más importante que una moneda común, para Europa [...], hecho adecuadamente, el resultado de nuestra batalla diaria es crear finalmente una opinión pública europea más homogénea, quiero decir respecto a Europa, creo que es la clave de la integración europea [...], tengo la impresión de que algo se mueve, es realmente el comienzo del comienzo [...], y un ejemplo de periodismo europeo orientado a una opinión pública europea fue precisamente la cobertura de la dimisión de la Comisión [el corresponsal se está refiriendo a los acontecimientos en torno a la dimisión en bloque de la Comisión Europea, el 16 de marzo de 1999, ante las sospechas de fraude puestas de manifiesto por un grupo de expertos auditores] (Siapera, 2002: 165-166). 
Las encrucijadas del periodista sobre asuntos comunitarios...

Es cierto que si buscamos una reacción unitaria y unánime de los europeos ante un acontecimiento comunitario, es más que probable que únicamente encontremos el caso que menciona este periodista, con el que realmente podríamos hablar de la emersión de una opinión pública europea unida contra el fraude y el escándalo y del encuentro de las diferentes culturas de la Unión Europea en una postura común a favor de la dimisión de aquella Comisión. Ese sentido de participación periodística activa en la construcción de una opinión pública europea pone de manifiesto la subordinación de la idea nacional al proyecto comunitario y presenta la pulsión nacionalista como problema y contratiempo a una verdadera y efectiva integración continental.

Si hay una idea verbalizada que sirva de ejemplo canónico de la pulsión europeísta frente a los encorsetamientos nacionales, ésa es la famosa frase de José Ortega y Gasset: España es el problema, Europa es la solución. Durante las últimas tres décadas, la mayor parte de la prensa española se ha caracterizado, por lo que al tratamiento de asuntos comunitarios europeos se refiere, por un abierto y explícito europeísmo.

Así como en gran parte de la prensa británica se ofrece una imagen de incompatibilidad entre lo nacional y lo comunitario, en la española, como en la italiana, aun estando igualmente presentes los discursos supranacional y nacional, no es tan fácil encontrar esa imagen de incompatibilidad. Incluso cuando en los periódicos españoles o italianos predomina el discurso del interés nacional, tal predominancia no implica necesariamente una visión negativa de la Unión.

La integración europea y la delegación de poder en instituciones supranacionales son consideradas por la sociedad española, incluidos los medios, como algo positivo y que se debe alentar. No se cuestiona la competencia y la legitimidad de la Unión para intervenir en determinados asuntos tradicionalmente reservados a la sola influencia nacional. De ahí que el interés español suele subsumirse en el interés de la Unión, y el desarrollo de ésta se representa en la gran prensa como también un desarrollo nacional. Y esto mismo también sucede en Italia, donde, no obstante, desde 1999, el discurso nacionalista se ha hecho más intenso en las páginas de los grandes diarios transalpinos y, sin caer en el antieuropeísmo, sí se ha comenzado a detectar cierto retraimiento hacia los intereses nacionales.

\section{LA TERCERA VÍA: EUROPA, LA OPORTUNIDAD NACIONAL}

Si en el apartado correspondiente considerábamos las nacionalidades como singularidades recelosas de la amenaza europeísta y, más adelante, eran consideradas como obstáculos a la sustanciación de una verdadera europeización, ahora, las nacionalidades pasan a ser contempladas como entidades dinámicas que tienen en Europa la oportunidad de progresar, de aprender, de transformarse, de crecer. La convivencia internacional se convierte en una gran escuela para el enriquecimiento y la maduración de los Estados, que ni se sienten amenazados ni en trance de desaparición:

Creo realmente que podemos aprender de los alemanes [...], porque son una de las pocas democracias reales, también de los griegos [...]. La prensa italiana tardó más que la alemana en entender que todo el proceso que condujo a la dimisión de la Co- 
misión [este corresponsal italiano se está refiriendo a los acontecimientos en torno a la dimisión en bloque de la Comisión Europea, el 16 de marzo de 1999] era un proceso de legitimación y de democracia [...], nosotros [los italianos] no entendimos esta verdad tan simple de que Europa es [...] un poder democrático, un poder que puede ser tenido por responsable, [...] nosotros [los italianos] llegamos tarde, porque nuestra opinión pública y nuestros lectores miraban, y todavía miran, a Europa como una forma de salvar a Italia, no es un asunto de estar seguros de que somos accionistas de una empresa común, sino más bien de algo más, [...] es cuestión de comprender que somos soldados, si no, [...] no creceríamos como democracia (Siapera, 2002: 170).

La nación es un alumno que tiene mucho que aprender de los otros, de las otras naciones:

Ellos [los jefes de la publicación] quieren que hagas un reportaje sobre la evolución de la calidad de las aguas en Halkidi, vale, te vas a Sithonia, a Cassandra [populares destinos turísticos situados en el norte de Grecia], a donde sea, hablas con la gente, con el ministro [...], tienes un gran reportaje, pero le falta algo [...], sí, tendrás un amplio punto de vista sobre la calidad de las aguas y de la responsabilidad de las autoridades locales a la hora de tener en cuenta el turismo, etc., etc. [...], pero quiero decir que podrías hacer comparaciones con Italia, con las playas italianas, con las playas españolas, con las danesas, eso sería mucho más interesante [...] para tus lectores. El principal interés de tus lectores es ¿debería ir este año a Sithonia? [...] pero [también] ¿debería apoyar la administración del consulado local para lo medioambiental de mi ciudad, [que] será próximamente elegido como alcalde, [...] me gustaría saber de algo no referido sólo a ese propio algo, sino en relación con. Luego necesitas tener a alguien aquí que te diga: [...] en Dinamarca, grandes cosas, las playas son horribles, espantosas, pero el agua es de gran calidad (Siapera, 2002: 171).

Desde el punto de vista que estamos analizando ahora, Europa es un ser tan orgánico como la propia nación, dos proyectos inacabados, en desarrollo, que son y serán un fruto dialéctico, un producto de la negociación. La supervivencia de la empresa de unificación continental ya no está vinculada al surgimiento de una opinión pública europea, si acaso, al contrario. Si antes hablábamos de la diversidad como debilidad de Europa, ahora es precisamente su fuerza. Las divergencias explícitas entre sus integrantes no empecen la marcha del proceso integrador, al contrario que en otras organizaciones internacionales:

La Unión Europea [...] trata con un gran conjunto de asuntos, con intereses abiertamente enfrentados, en la OTAN todo es secretismo hasta que no se alcanza un acuerdo (Siapera, 2002: 172).

La armonía ya no es condición sine qua non para una maduración que requiere sus sacrificios, sus contratiempos, porque de ellos cobra su vigor:

Creo que la dimisión de la Comisión -nos cuenta un corresponsal en referencia a los acontecimientos del 16 de marzo de 1999- fue extremadamente positiva, dolorosa, la democracia nunca, nunca es indolora, la gente que piense que Europa es armónica es probablemente la menos democrática (Siapera, 2002: 172). 
Las encrucijadas del periodista sobre asuntos comunitarios...

La ósmosis de culturas, de modos de entender la res pública, propicia el progreso, el crecimiento, la mejora:

\begin{abstract}
Es una cultura, una nueva cultura que viene del norte [de Europa], [...] no puedes decir no soy políticamente responsable [el corresponsal se sigue refiriendo a los acontecimientos en torno a la dimisión en bloque de la Comisión, el 16 de marzo de 1999], porque eso te convierte por sí mismo en un político inútil, porque por definición siempre eres políticamente responsable, decir que no lo sabías es motivo suficiente para que te vayas, y a eso apelaron los auditores, el grupo de expertos, y fue una conmoción, creo, para muchos políticos sureuropeos, pero ahora son conscientes de su absoluta responsabilidad (Siapera, 2002: 172).
\end{abstract}

Europa y la nación no son en absoluto incompatibles, ambas son posibles y ambas forman parte de un esperanzador futuro común a las dos, en aras al cual están abocadas a entenderse y a complementarse.

\title{
5.1. El periodismo bidimensional
}

El espacio periodístico que surge de este último posicionamiento ideológico que hemos dado en llamar tercera vía y que concibe tanto Europa como la nación como organismos dinámicos y sinérgicos, es probablemente el más abundante de los registros periodísticos posibles en relación con la información que se publica en gran parte de los diarios europeos sobre la Unión Europea. Dado que ahora los límites nacionales se expanden, pero sin desaparecer, las nacionalidades ni están amenazadas por el proyecto europeísta ni le estorban a éste, lo que periodísticamente hablando se traduce en resultados profesionales cooperativos preferentemente centrados en lo que ocurre allende las fronteras propias. De hecho, un tipo de ejercicio profesional muy recurrente es el que tiende a proporcionar información comparada, es decir, a establecer comparaciones entre lo nacional y su paralelo en otros países. Un emplazamiento periodístico como el bruselense, donde, dado el gran número de corresponsales allí desplazados y la gran cantidad de fuentes presentes, las posibilidades de cooperación e intercambio son enormes, es en este sentido óptimo para tal práctica. Eugenia Siapera denomina post-nacionalista al periodismo alumbrado bajo esta última luz ideológica expuesta, puesto que si bien no es declaradamente europeísta, ya no es el interés nacional el exclusivo Leitmotiv del esfuerzo periodístico. El periodista da prioridad a la dimensión política de los acontecimientos antes que a la nacional y muestra preocupación por el futuro del proyecto europeo, por cuyo adecuado desarrollo debe velar en el mismo grado que debe hacerlo por lo relativo a su propio país.

En este sentido, escribe Christopher Huhne a propósito del caso británico:

La mayor parte de la gente se da cuenta de que la amenaza a la identidad cultural británica no viene de Bruselas, sino de nuestros seductores primos de allende el Atlántico con su convincente fábrica de sueños hollywoodiense. Los valores sociales británicos son más europeos que americanos, como lo refleja nuestro relativamente fuerte compromiso con el estado del bienestar y la relativamente alta provisión de servicios sociales. La mayor parte de la gente sabe que no hay conflicto entre ser británico, inglés y de Yorkshire. Ser europeo es sólo otra capa de nuestra identidad (Beetham, 2001: 170). 
Ahora, al articular periodismo con las teorías sobre Europa y la nación expresadas en el constructo que hemos llamado tercera vía, tenemos que el objetivo del periodista es animar el debate no sobre si Europa debe o no debe existir, sino sobre qué forma debe adoptar. Se parte de un hecho consumado y necesario para tal teorización: la existencia real y consolidada de la entidad europea. La postura crítica no es aquí destructiva y, por lo tanto, tampoco antieuropeísta:

\begin{abstract}
Pienso que es realmente estúpido proteger a alguien que no merece la pena de ser protegido, nosotros atacamos a nuestro comisario con artículos muy críticos [el periodista habla de la crisis que condujo a la dimisión colectiva de la Comisión Europea en marzo de 1999], [...] nos enfrentamos a uno de nuestros directores generales, porque no veo ningún argumento nacional para protegerle: ¿por qué? Yo quiero un buen comisario, como el alemán, quiero que sea un buen comisario internacional europeo [...], si queremos tener una Europa común, debemos ser capaces de criticar en cualquier momento a cualquier comisario, si hace algo negativo, esto sería una verdadera Europa [...] (Siapera, 2002: 176).
\end{abstract}

Este testimonio trasluce la actitud de un periodista que da prioridad a la dimensión política de los acontecimientos europeos antes que a la nacional -0 , al menos, al mismo nivel que a la nacional-y muestra preocupación por el futuro del proyecto, por cuyo adecuado desarrollo, como decíamos párrafos atrás, vela en el mismo grado que vela por el de su propio país, sin rastro de sesgo en sus preferencias, como también pone de manifiesto el siguiente testimonio de Félix Monteira, ex corresponsal de El País en Bruselas, que sitúa lo nacional y lo europeo a un mismo nivel: El periodista que está en medio de todo este marasmo, tiene por un lado al enemigo Comisión y por otro al enemigo Estado (Sánchez Martínez, 1994: 27).

\title{
6. CONCLUSIONES
}

Las ideas que han guiado estas páginas han sido, por un lado, la de sondear los significados de nacionalidad y europeidad que circulan entre los corresponsales de prensa desplazados a Bruselas y, por otro lado y principalmente, examinar lo que sucede, es decir, observar qué espacio periodístico se abre al articular esos significados con el ejercicio profesional del periodismo. $Y$ de tales articulaciones han surgido los tres grandes espacios aludidos: el periodismo euroescéptico, el periodismo europeísta y el periodismo que hemos denominado bidimensional, en resumen, un periodismo centrado en lo nacional, un periodismo centrado en lo europeo y un periodismo que Siapera denomina post-europeísta, caracterizado por el salto desde una postura europeísta asociada a un activismo periodístico en favor de la construcción comunitaria a una postura más puramente política y menos propagandística.

Estos espacios del periodismo europeo por nosotros identificados coexisten en un marco de significados de esta disciplina abierto. Aunque no podemos asegurar que los registros antedichos agoten dicho marco, sí parecen cubrir una parte muy considerable del mismo. Quizás otros estudios posteriores identifiquen o reconstruyan otros repertorios constitutivos de la actividad periodística en relación con los asuntos comunitarios que puedan ser añadidos a los aquí expuestos para enriquecer y aclarar el panorama. 
Las encrucijadas del periodista sobre asuntos comunitarios...

Las aludidas encrucijadas del periodista-corresponsal que hemos descrito son producto de algunas de nuestras investigaciones en torno al tratamiento periodístico de los asuntos comunitarios europeos practicado por los profesionales más cercanos al proceso político de la Unión Europea. Han sido captadas en las opiniones de quienes ejercen -o han ejercido- corresponsalías en Bruselas. Quizás estos tres grandes condicionamientos identificados no son incompatibles o mutuamente excluyentes, pero son, de hecho, irreducibles unos a otros.

El periodismo sobre asuntos comunitarios europeos casi siempre se ejerce de manera articulada con una serie de discursos relevantes. También queda patente la existencia de tensiones -y aun de contradicciones- en el espacio de la práctica periodística dentro de nuestro marco de referencia: las corresponsalías desempeñadas en Bruselas, capital de la Unión Europea.

No es fácil encontrar registros totalmente puros de ninguno de los tipos de periodismo emanados de las consideraciones apuntadas sobre los conceptos de nacionalidad y europeidad, pero en nuestras investigaciones sobre el tratamiento periodístico de los asuntos relacionados con la Unión Europea, siempre hemos podido detectar e, incluso, clasificar las unidades de texto analizadas bajo alguno de los registros descritos.

No conviene caer en valoraciones fáciles y simplistas de si el discurso público de un país es claramente pro-europeo o claramente antieuropeo. El discurso público es siempre complejo y ambiguo, como, especialmente, pone de manifiesto el estudio del caso británico respecto a la potencial sustitución de la libra esterlina por el euro. La ambigua postura británica sobre la adopción o no de la nueva moneda responde a una compleja serie de variables. A los motivos históricos se le suman motivos económicos, sociales, culturales y, sobre todo, políticos (falta de liderazgo en la causa pro-euro). La ambivalencia también está presente en la prensa británica, en la que se detectan grandes cargas de crítica y debate y en la que el recurso de los periodistas a los registros profesionales en relación con el hecho comunitario identificados en este artículo varía ostensiblemente, cualitativa y cuantitativamente, respecto a los casos de otros países de la Unión Europea, como España e Italia. No obstante, la complejidad del discurso público no es característica exclusiva de la sociedad británica, también Italia, España y, en general, el resto de los países comunitarios ofrecen muestras de ambivalencia ante el hecho comunitario europeo.

Retomando las hipótesis de partida que exponíamos en los párrafos iniciales de este artículo y a la vista de lo posteriormente expuesto, hemos verificado, primero, la existencia de determinados condicionamientos ideológico-culturales que influyen sobre el corresponsal de prensa que desarrolla su labor en Bruselas y, segundo, hemos verificado la influencia de tales condicionamientos sobre los resultados periodísticos del trabajo de esos corresponsales. 


\section{REFERENCIAS BIBLIOGRÁFICAS}

BEeTHAM, R. (ed.) The Euro Debate. Persuading the people. London: The Federal Trust for Education and Research, 2001.

BLUMLER, J. G.; GUREVITCH, M. The Crisis of Public Communication. London and New York: Routledge, 1995.

DE VREESE, C. H., "Europe in the News. A Cross-National Comparative Study of the News Coverage of Key EU Events", European Union Politics, vol. 2 (2001), núm. 3, pp. 283-307.

DE VREESE, C. H.; PETER, J.; SEMETKO, H. A., "Framing Politics at the Launch of the Euro: A Cross National Comparative Study of Frames in the News", Political Communication, núm. 18 (2001), pp. 107-122.

DÍAZ NOSTY, B. (dir.), La prensa diaria en la UE. Madrid: Asociación de Periodistas Europeos, 2003.

- (2002) Infoeuropa 2002: La prensa diaria en la UE. Estructura y proyección digital. Madrid: Asociacion de Periodistas Europeos.

- (1996) V Infoeuropa: La Unión Europea en los medios de comunicación 1996 - European Union in the media 1996. Madrid: Asociación de Periodistas Europeos y Fundesco.

- (1995) IV Infoeuropa: La Unión Europea en los medios de comunicación 1995 - European Union in the media 1995. Madrid: Asociación de Periodistas Europeos y Fundesco.

- (1994) III Infoeuropa: La Unión Europea en los medios de comunicación 1994 European Union in the media 1994. Madrid: Asociación de Periodistas Europeos y Fundesco.

- (1993) II Infoeuropa: La Unión Europea en los medios de comunicación - European Union in the media. Madrid: Asociación de Periodistas Europeos y Fundesco.

- (1991) I Infoeuropa: Los medios en la construcción de la unidad europea (Análisis de la información sobre la CE en la prensa y la televisión españolas). Madrid: Asociación de Periodistas Europeos y Fundesco.

KEARNEY, H. Four Nations or One? En CRICK, B. (ed), National Identities: The Constitution of the United Kingdom. Oxford: Blackwell Publishers, 1991, pp. 1-6.

POTTER, J. Representing Reality. London: Sage, 1996.

PEPERMANS, R.; MÜLLER-PETER, A., "Differences in Information Requirements Among European Citizens: More Psychology Than Socio-Demographics", Journal of Consumer Policy, núm. 22 (1999), pp. 81-90.

PÉREZ PLAZA, V., "The Euro as a Political Communication Process: Quality Requirements", Journal of Consumer Policy, núm. 22 (1999), pp. 135-147.

PETER, J.; SEMETKO, H. A.; DE VREESE, C. H., "EU Politics on Television News. A Cross-National Comparative Study“, European Únion Politics, vol. 4 (2003), núm. 3, pp. 305-327.

LACLAU, E.; MOUFFE, Ch. Hegemony and Socialist Strategy: Towards a Radical 
Las encrucijadas del periodista sobre asuntos comunitarios...

Democratic Politics. London: Verso, 1985.

POTTER, J.; WETHERELL, M. Discourse and social psychology: beyond attitudes and behaviour. London: Sage, 1987.

RISSE, T. To Euro or Not to Euro. EMU and Identity Politics in the European Union [en línea]. Oslo: Arena Working Papers, WP 1/98, 1998. [Consulta: 26 marzo 2008]. $<$ http://www.arena.uio.no/publications/wp98_1.htm>

SÁNCHEZ MARTÍNEZ, M. (ed.) Periodismo Especializado e Información Comunitaria. Salamanca: Facultad de Ciencias de la Información de la Universidad Pontificia de Salamanca, Representación en España de la Comisión de las Comunidades Europeas, 1994.

SEMETKO, H. A.; VALKENBURG, P. M., "Framing European Politics: A Content Analysis of Press and Television News", Journal of Communication, vol. 50 (2000), núm. 2, pp. 93-109.

SIAPERA, E. Read All About It: Journalism, Europe and Politics. A Study on Journalism. Florence: Department of Political and Social Sciences, European University Institute, 2002.

TRIANDAFYLLIDOU, A. Negotiating nationhood in a changing Europe: views from the press. Lewiston, New York: The Edwin Mellen Press, 2002.

TRIANDAFYLLIDOU, A. "Research Note: The Launch of the Euro in the Italian Media. Representations of Political and Economic Integration", European Journal of Communication, vol. 18 (2003), núm. 2, pp. 255-263.

WERDER, O. "Debating the Euro. Media Agenda-Setting in a Cross-National Environment", Gazette: The International Journal for Communication Studies, vol. 64 (2002), núm. 3, pp. 219-233.

WETHERELL, M. "Positioning and interpretive repertoires: conversation analysis and post-structuralism in dialogue", Discourse and Society, vol. 9 (1998), núm. 3, pp. 387-412.

WETHERELL, M.; POTTER, J. Mapping the language of racism: discourse and the legitimation of exploitation. Hemel Hempstead: Harvest-Wheatsheaf, 1992.

\section{Breve semblanza del autor}

Joaquín Sotelo es periodista profesional y profesor de Estructura de la Comunicación en la Facultad de Ciencias de la Información de la Universidad Complutense de Madrid. La mayor parte de sus investigaciones, incluida su tesis doctoral, se han centrado en asuntos relacionados con la Unión Europea. Gran parte de sus trabajos como investigador los ha realizado en prestigiosas instituciones académicas europeas, como el Instituto Universitario Europeo de Florencia, Oxford University o el University College of York. 